\title{
Assessing a Rural Academic-Community Partnership Using Ripple Effect Mapping
}

\author{
Jennifer Taylor, Sarah Goletz \& Jim Ballard
}

\begin{abstract}
As Area Health Education Centers (AHEC) expand their efforts to improve the distribution and diversity of the healthcare workforce, one common question is how these activities impact their local communities. Ripple Effect Mapping (REM) is an evaluation method designed to assess a program's intended and unintended impacts, social capital, and partner reciprocity. This study used REM to uncover and explore the intended and unintended impact of a rural AHEC in a 14county region. The findings of this study provide direction to the AHEC in relation to strengthening their partnerships, social capital, and improving the health workforce in their region.
\end{abstract}

Key words: area health education centers, community/academic partnership, community development, evaluation, impacts, outcomes, Ripple Effect Mapping

This is the author's manuscript of the article published in final edited form as:

Taylor, J., Goletz, S., \& Ballard, J. (2020). Assessing a rural academic-community partnership using ripple effect mapping. Journal of Community Practice, 28(1), 36-45. https://doi.org/10.1080/10705422.2020.1716286 
Assessing a Rural Academic-Community Partnership Using Ripple Effect Mapping

\section{Background}

The Area Health Education Centers (AHEC) program is a community engaged initiative that has evolved over the past five decades in an effort to positively affect the health workforce. Specifically, the AHEC program emerged as a result of the Carnegie Commission on Higher Education in 1972 to address health workforce shortages and the geographic maldistribution of health professionals and to affect the quality, utilization, and efficiency of primary healthcare services in medically underserved communities (Fowkes, Campeau, et al., 1991; Fournier, 1998; Nottingham \& Lewis, 2008). Training students in rural and underserved communities is vital for health workforce development and AHECs work to develop, recruit, train, and retain health professionals for work in these communities. From a population health perspective, training in underserved areas help students understand the factors that are responsible for poor health outcomes in vulnerable populations in addition to gaining an appreciation of diversity, cultural variations, and related stigmas occurring in these communities (Patel, 2017). The AHEC program connects academic and community resources to address these workforce needs through a community-engaged collaboration linking the academic resources of health professions programs at universities with community partners. Despite the longevity of this program, the literature focused on its outcomes and impact remains scant.

The preponderance of the existing literature focuses on the direct outcomes of AHECsupported programs and is often limited to programmatic descriptions and satisfaction data from AHEC participants (Fowkes, Blossom, et al., 2007, Nottingham \& Lewis, 2008). This is not surprising because most of the evaluations of AHECs and similar programs are conducted through a positivist perspective, often through a social science theoretical lens. The goal of such 
research is to reduce the complex interactions occurring in the community into their basic elements that describe, as well as possible, a cause and effect relationship (Creswell \& Creswell, 2017). The approach in this study was to utilize a social-constructivist lens of inquiry because of the complex and multi-systematic milieu of community engaged work. As such, we hoped to embrace the dynamic complexity of views rather than reduce the impact of the work to its discrete and constituent parts. This approach is informed by community extension and other community-engaged undertakings that demonstrate that there are both intended and unintended outcomes of community-engaged programs for the communities in which they operate. Using the interpretivism philosophical framework rather than the post-positivism approach provides community members the open dialogue to share their experiences and perceptions (Greene, 1994). To date, this is an area of investigation that has not yet been explored in AHEC.

This study describes the qualitative impact resulting from one AHEC center's engagement with their community in a predominantly rural 14-county region in the Midwest. The center's small staff, engages a 15-member governing board with representation from community leaders from critical access hospitals, long-term care facilities, behavioral health, academic programs in the health professions, workforce development, and practicing healthcare practitioners.

Like many organizations working in rural underserved areas, the Indiana AHEC Network uses human and social capital (Dubos \& Cook, 2017) to aid their partners in facilitating health workforce development programs designed to improve the representation of individuals from under-represented minority, disadvantaged, and rural backgrounds in their community. The goal of this study was to uncover and explore the intended and unintended outcomes in the East Indiana AHEC (EI-AHEC) region that can be attributed to the presence of AHEC. A Ripple 
Effect Mapping (REM) methodology was employed to assess both intended and unintended outcomes and impact of community engaged interventions. Chazdon et al. (2017), describe this approach as one that engages the many voices of community members. It provides an opportunity for stakeholders in the community and at the programmatic level to listen, learn, and be motivated by each other. As such, it transcends the finite limitation of the positivist and postpositivist worldviews employed in the past studies to create dialogue among community members and to uncover the intricacies of the work that AHEC performs. It is an appropriate method given the social constructivist orientation of this study.

REM has been utilized across a variety of contexts such as assessing the impact of a citizen-led initiative to address poverty (Welborn et al., 2016), gauging the impact of a community-driven business retention and expansion process (Darger, 2014), and identifying outcomes of a community-based program (Olfert et al., 2018). Research shows that REM sessions have many benefits, for example, the low cost of facilitating a two-hour session with a group of participants (Kollock et al., 2012; Peterson \& Skolits, 2019). REM allows for the capture of the intended and unintended impacts of complex programs. The complexity of health workforce development programing in rural areas provides an ideal setting to use REM as a method of identifying community impact that would have otherwise remained unknown. Opportunities such as REM allow organizations to identify and understand connections among community members, organizations, and resources, as well as to further develop their network and social capital in order to create energy and momentum to further work in the field (Kollock et. al., 2012; Peterson \& Skolits, 2019; Emery et al., 2015). Specifically, the process of REM was used help identify how the EI-AHEC broadly impacted or influenced the community they serve. This study received exempt approval by the Institutional Review Board of Indiana University. 


\section{Methods}

\section{Participant Selection Criteria}

Invitations to participate were strategically sent to individuals who were heavily involved in the EI-AHEC organization (internal stakeholders), as well as those with a peripheral awareness of the program (external stakeholders). As part of the event registration process, participants were asked to report their familiarity with the EI-AHEC based on a 3-point Likert scale of Very Familiar, Somewhat Familiar, and Not Very Familiar. Twelve individuals participated in the EI-AHEC REM session, consisting of an equal number of external and internal stakeholders. Participants were from a variety of settings, included community mental health center $(n=1)$, a high school $(n=1)$, secondary education institutions $(n=5)$, career centers $(n=2)$, healthcare organizations $(n=2)$, and a community-based non-profit organization $(n=1)$. In terms of familiarity with the EI-AHEC, four participants reported they were very familiar with the program, seven reported they were somewhat familiar, and one participant reported feeling they were not very familiar with the program. Because of the mix, three interview pairs of participants consisted of one individual who was very familiar and one individual who was somewhat familiar. Two interview pairs connected two individuals who both self-reported as somewhat familiar. The final interview pair was an individual who self-reported as very familiar and an individual who reported they felt not very familiar.

\section{Procedure}

There are four main components of the REM session: Appreciative Inquiry (AI), Participatory Approach, Interactive Group interviewing and Reflection, and Mind Mapping (Chazdon et al., 2017). Session participants were selectively paired in groups of two consisting of an internal stakeholder and an external stakeholder. Each pair completed one-to-one 
interviews using the pre-identified AI questions. The three pre-identified AI questions were asked with the specific goal of determining how the EI-AHEC has made an impact on the community within the prior 24 months. Specific AI questions used in this session included:

- What is a highlight, achievement, or success that you have had over the past 24 months that was related to a partnership with the EI-AHEC?

- What unexpected things have emerged in your work as a result of working with the EIAHEC?

- What connections with others - new and/or deepened - have you made a result of the EIAHEC's work in this region over the past 24 months? What did those connections lead to? After the individual interviews were completed, all participants reported their corresponding partners' answers to the AI questions using the Interactive Group Interviewing process. During the participants reporting, researchers developed a live mind-map using the software $\mathrm{XMind}^{\odot}$ in order to provide real-time member checking to increase the validity of the results. Mind mapping is a data visualization tactic where as participants are engaged in sharing their partner's answers from the AI interview, one of the session facilitators is using software designed to display on a large screen the responses for each question. The use of mind mapping allows participants the opportunity to view both the overarching picture and their own level of detail simultaneously (Chazdon et al., 2017).

During the session, participants are engaged in an evaluation process using the Participatory Approach in REM. In this instance, participants were able to view the live mindmap as it was developed and provide clarification and feedback in real time. At the conclusion of the two-hour group interviewing session, follow-up interviews were conducted with study participants to ensure accuracy of the mind-map and to further flesh out identified themes and 
topics. Inductive coding was performed by the three facilitators of the session to identify the main themes and subsequent impacts or ripples reported by stakeholders throughout the community. The results of the session were shared again with session participants as a form of validation of the results.

\section{Results}

Four major themes emerged from the Appreciative Inquiry questions used during the REM session: increasing opportunities, increasing collaborations and connections, continuing education support, and unexpected realizations (Table 1). Each core theme was further analyzed to determine the level of impact or ripple in the community. For example, session participants initially shared that the EI-AHEC has had with providing resources for a regional simulation center to open the doors for student experiences (primary ripple). As the discussion progressed, it was reported that due to the EI-AHEC involvement, students were able to engage in a simulation on caring for individuals with disabilities (secondary ripple), that resulted in the students being more confident to care for individuals with disabilities (tertiary ripple).

Table 1: Description of Themes and Subthemes

\begin{tabular}{|l|l|l|}
\hline Main Themes & Sub-Themes & Levels of Ripples \\
\hline $\begin{array}{l}\text { Increasing } \\
\text { opportunities }\end{array}$ & $\begin{array}{l}\text { Educational pipeline support } \\
\text { Simulation partnerships } \\
\text { Clinical partnerships and experiences }\end{array}$ & 6 levels of ripples \\
\hline $\begin{array}{l}\text { Increasing } \\
\text { collaborations and } \\
\text { connections }\end{array}$ & $\begin{array}{l}\text { AHEC as a bridge between higher education } \\
\text { and community members } \\
\text { AHEC helping to develop new programs } \\
\text { Connecting students to local scholarship } \\
\text { programs in health care }\end{array}$ & 4 levels of ripples \\
\hline $\begin{array}{l}\text { Continued education } \\
\text { support }\end{array}$ & $\begin{array}{l}\text { Conference support } \\
\text { Dissemination of knowledge gained } \\
\text { Employees as lifelong learners }\end{array}$ & 3 levels of ripples \\
\hline $\begin{array}{l}\text { Unexpected } \\
\text { realizations. }\end{array}$ & $\begin{array}{l}\text { Limited local resources } \\
\text { AHEC provides additional resources }\end{array}$ & 3 levels of ripples \\
\hline
\end{tabular}


Increasing opportunities. Three main sub-themes developed as a result of identifying the increase in opportunities. The most common sub-theme dealt with educational support for pipeline activities. Most notably a participant shared a statement from one of their high school students about participating in career counseling opportunities through the EI-AHEC: "I understand my career path now. I know what I have to do in college to reach my degree." A faculty member at an institute of higher education reported that a pre-nursing student made a similar statement in regards to learning about the importance of working as a team when one becomes a health professional: "I understand that in nursing-team work, perseverance, and leadership are vital to being successful."

Another sub-theme identified within the theme was EI-AHEC's continued partnership with the regional simulation consortium. Participants in simulation activities report that working with EI-AHEC and the simulation consortium allowed health profession students gain additional hours of simulation, thus increasing their perceived comfort when transitioning into practice. Instructors noticed that students highly valued the additional simulation hours and they saw an increase in their test scores and general nursing knowledge.

Increasing clinical partnerships was another sub-theme that emerged during the session. Participants noted that the clinical experiences helped model professional behavior for students and helped them learn cultural humility. Strong partnerships between AHEC and new experiential clinical sites was identified as a major ripple. A powerful comment was shared by a participant who stated: "I always go to AHEC when I want to try something new. EI-AHEC encourages new ideas and creativity [which] results in a 'playful' attitude about learning. EIAHEC is really good at planting seeds that sprout." Many participants identified that the support that AHEC provides to community partners and clinical preceptors helps constituents understand 
that there is more to precepting than just a time commitment - it is an investment in the community.

Increasing collaborations and connections. One of the more prominent subthemes that emerged out of this main theme was the use of EI-AHEC as a 'bridge'. Many participants stated that EI-AHEC has bridged the gap between academia and the community. One of the most prominent statements came from a healthcare organization representative who stated that: "EIAHEC's connections have allowed us to provide our employees with opportunities they wouldn't normally have. Their connection to students has allowed us to create scholarships so students do not have to take on student loan debt."

Participants indicated that the partnership with the EI-AHEC has provided an opportunity to have a greater reach with students across the area and, subsequently, one organization gave over five million dollars in student scholarships enabling students to graduate with reduced debt burden. Several iterated that using EI-AHEC as a bridge from community to practice has helped deepen their relationships across all sectors. One of the strongest statements about this bridge was: "It is hard to get people to understand what the healthcare and training needs are, but EIAHEC really gets it. They really do. They are responsive to our needs and the needs of the community in which they serve." The majority of participants mentioned that they now have a better understanding of what other organizations in the community are doing as a result of participating in the REM session. Organizations that previously have not partnered together (a high school, career center, and a community mental health center) expressed the intent to collaborate together on future initiatives.

Continued education support. Three ripples/sub-themes were identified in relation to continuing education and support. Participants stated that continuing education opportunities are 
vital for the healthcare professions to maintain their licensure and credentials. EI-AHEC's support with conference attendance provided several participants the opportunity to connect with others from the west coast and the east coast. Through these experiences, participants disseminated their knowledge gained and best practices with other healthcare practitioners within the community who are encountering similar struggles. Another prominent sub-theme identified emphasized that the support from the EI-AHEC enables health professionals to become life-long learners. One participant mentioned the benefits that result from the continuing education support provided to her staff members and coworkers: "They are more confident now. They go to meetings and students are there. The students then leave and want to talk about trauma outside of school". The session on community impact highlighted the fact that while partners utilized AHECS on a number of different programs or initiatives, none appeared aware of the full scope of services and resources the AHEC program could provide throughout the region.

Unexpected realizations. The unexpected realizations fell predominantly under two subthemes: lack of local resources and the underutilization or awareness of AHEC resources. Many participants mentioned that they did not realize that AHEC provided resources that crossed the spectrum of both primary care and mental health services. A sentiment repeated throughout the REM session was the trust and dependability of the EI-AHEC reputation. One participant stated: "EI-AHEC is my go-to organization when I want to try something new in the classroom. We know that we can trust them and they have the resources".

\section{Discussion}

The EI-AHEC's mission is to improve health by recruiting, educating, and retaining healthcare professionals for rural and medically underserved communities in eastern and southeastern Indiana. Achieving this mission is not possible without collaboration with 
community partners across their 14-county region. Partnerships cannot exist or be sustainable without reciprocity and mutual benefits. Conducting the Ripple Effect Mapping session allowed for an opportunity to identify the level of unknown influence the EI-AHEC has had in their region within the past two years. Incorporating a social-constructivist perspective afforded by REM expanded identification and understanding of community impacts beyond the level of traditional, positivist influenced methodologies, uncovering a more complete and dynamic appreciation of the AHEC program's influence.

The ripples identified by session participants within each core theme demonstrated the unknown and unintended far-reaching impact of this program. The qualitative findings revealed further connections and opportunities related to enhancing education in the areas of mental health, aging, and simulations. An unexpected impact of this REM session was the shift in the group dynamics among the study participants. In addition to developing a richer understanding of the capacity of the EI-AHEC, many participants began to brainstorm ways to enhance partnerships in the future. As a result of the session, participants asked for an all-inclusive newsletter in order for partners and stakeholders to remain informed about the different EIAHEC supported initiatives.

This REM session brought together the skills and knowledge of constituents from various levels of education and health systems to help understand the functioning of intended programming and how it enhances, interfaces with, and can be expanded by community partnerships. The impact brought about by interacting with simulation experts and resources is the most salient example of this. Participants seem to be able to better view the interconnectedness among universities, simulation centers and practicing health professionals as an integrated 'whole' as opposed to discreet entities. The increased awareness of the intersection 
between various entities in education and healthcare was apparent in the REM session based on the number of statements about future collaboration among participants of various sectors.

The limitation of this study is the potential bias in both participant selection and reporting (data collection). While the team at the EI-AHEC worked to recruit participants that either had an intimate level of knowledge about its work or a peripheral awareness about the AHEC, there may be an implicit bias among the representation of the participants. With the self-reporting nature of the tool, participants may have had a limited perception of the program, thus unable to identify any negative outcomes associated with the program. Although the researchers facilitating the session probed for negative outcomes, none were identified beyond the perception that partners were underutilizing the program. The small sample size within this REM session and the specific nature of the questions result in a limited ability to generalize the findings across other similar programs.

\section{Conclusion}

This study demonstrates the value of Ripple Effect Mapping as a tool for assessing collaborations and partnerships, the extent to which it can assess the impacts of AHEC had not been explored until now. The REM tool served as a straightforward method to assess both the impact of AHEC's health workforce initiatives, and the sustainability of various partnerships. The findings of this study provide direction to the EI-AHEC related to further strengthening their partnerships, and human and social capital in order to continue improving the healthcare workforce in their region. As expected, AHEC's role in providing continued professional development to community practitioners was appreciated, yet it was surprising to learn how important this service is to the community and how the results transcend state boundaries and promote life-long learning. Finally, it was important to discover the unexpected realizations 
among participants that AHEC is an underutilized partner. For example, many participants were familiar with AHEC within the narrow scope of their existing partnership, but was not aware of the other resources in the field of health workforce development in which they can partner with AHEC. 


\section{References}

Chazdon, S., Emery, M., Hansen, D., Higgins, L., \& Sero, R. (2017). A field guide to Ripple Effects Mapping. University of Minnesota Libraries Publishing. http://hdl.handle.net/11299/190639

Creswell, J. W., \& Creswell, J. D. (2017). Research design: Qualitative, quantitative, and mixed methods approaches. Sage Publications.

Darger, M. (2014). Capturing the ripples from community-driven business retention and expansion programs. Journal of Extension, 52(2).

\section{https://www.joe.org/joe/2014april/tt6.php}

Dubos, R., \& Cook, K. (2017). Social capital: Theory and research. Routledge.

Emery, M., Higgins, L., Chazdon, S., \& Hansen, D. (2015). Using Ripple Effect Mapping to evaluate program impact: Choosing or combining the methods that work best for you. Journal of Extension, 53(2), 2TOT1. https://www.joe.org/joe/2015april/tt1.php

Fournier, A. (1998). Medical education in underserved communities: Experience from an urban area health education center. Journal of Health Care for the Poor and Underserved, 9(2), 109-116. doi:10.1353/hpu.2010.0157

Fowkes, V. K., Campeau, P., \& Wilson, S. R. (1991). The evolution and impact of the national AHEC program over two decades. Academic Medicine, 66(4), 211-220.

Fowkes, V. K., Blosson, J. H., Anderson, H. K., \& Sandrock, C. (2007). Emergency preparedness for health professionals in a statewide AHEC program: The first two years, Academic Medicine, 82(8), 781-787.

Greene, J. C. (1994). Qualitative program evaluation: Practice and promise, in N. K. Denzin \& Y. S. Lincoln (Eds.), Handbook of qualitative research (pp. 530-544) Sage. 
Kollock, D. H., Flag, L., Chazdon, S., Paine, N., \& Higgins, L. (2012). Ripple Effect Mapping: A "radiant" way to capture program impacts. Journal of Extension, 50(5), 5TOT6. https://www.joe.org/joe/2012october/tt6.php

Nottingham, L., \& Lewis, M. (2008). AHEC in West Virginia: A case study. Journal of Rural Health, 19(1), 42-46. https://doi.org/10.1111/j.1748-0361.2003.tb00540.x

Olfert, M. D., Hagedorn, R. L., White, J. A., Baker, B. A., Colby S. E., Franzen-Castle, L., Kattelmann, K. K. , \& White, A. A. (2018). An impact mapping method to generate robust qualitative evaluation of community-based research programs for youth and adults. Methods and Protocols, 1(3). https://doi.org/10.3390/mps1030025.

Patel, A. (2017). Understanding the importance of medical student clerkships in poor health outcome regions served by Area Health Education Centers (AHECs) in impoverished locations of southern United States. Archives of Public, 75(7). https://doi.org/10.1186/s13690-017-0175-y

Peterson, C., \& Skolits, G. (2019) Evaluating unintended program outcomes through ripple effects mapping (REM): Application of REM using grounded theory. Evaluation and Program Planning, 76. https://doi.org/10.1016/j.evalprogplan.2019.101677

Welborn, R., Downey, L., Dyke, P., Monroe, P., Tyler-Mackey, C., \& Worthy, S. (2016). Turning the tide on poverty: Documenting impacts through Ripple Effect Mapping. Journal of Community Development, 47(3), 385-402.

https://doi.org/10.1080/15575330.2016.1167099 